\title{
Turismo, patrimonio cultural y desarrollo local. Evaluación del potencial turístico de aldeas rurales en la provincia de Entre Ríos, Argentina ${ }^{1}$
}

\author{
Claudia Toselli* \\ Universidad del Salvador (Argentina)
}

\begin{abstract}
Resumen: Distintos organismos internacionales establecen que el turismo con base en el patrimonio cultural puede constituirse en un instrumento de inclusión y dinamización socioeconómica de un territorio. En este sentido, las áreas rurales como lugar de vida y de producción se ven como nuevos espacios a descubrir a través de sus tradiciones, sus paisajes, su gastronomía, su artesanía y/o su cultura. Sin embargo, para que pueda efectivizarse un proceso de desarrollo local-rural basado en la actividad turística, el primer paso consiste en contar con información previa y, en particular, conocer los recursos/atractivos disponibles. En esta línea, a partir de distintas investigaciones previas sobre turismo y patrimonio realizadas en las aldeas San Antonio, San Juan y Santa Celia, provincia de Entre Ríos (Argentina), se consideró tomar estas localidades como estudio de caso. En ellas predominan descendientes de alemanes provenientes de la región del Volga (Rusia) arribados a fines del siglo XIX, y tienen la particularidad de haber preservado hasta el presente valiosas tradiciones y costumbres. De esta manera, el objetivo del trabajo fue realizar una evaluación del potencial turístico-cultural de dichas aldeas. El trabajo forma parte de un proceso de investigación de tipo exploratorio, en el cual se realizaron consultas de fuentes primarias y secundarias, la elaboración de una ficha relevamiento y de una matriz de evaluación del potencial turístico de las aldeas. Dentro de los principales hallazgos se detectó, que a pesar del valioso patrimonio cultural tanto tangible como intangible existente, no hay un registro oficial de estos bienes. Por lo tanto, disponer de una información integral al respecto, permitiría impulsar acciones, tales como: promover una mayor difusión entre la propia comunidad; gestionar determinada normativa y/o financiamiento que permita preservar sitios relevantes; identificar atractivos que puedan integrarse a una posible oferta turística-cultural, y analizar junto a la comunidad, futuros emprendimientos en base al patrimonio cultural.
\end{abstract}

Palabras Clave: Turismo cultural; Turismo rural; Patrimonio cultural; Desarrollo local; Argentina.

Tourism, cultural heritage and local development. Evaluation of the tourism potential of rural villages in the province of Entre Ríos, Argentina.

\begin{abstract}
Many international organizations have posited tourism based on cultural heritage as a tool to be deployed toward greater inclusion and socio-economic development. Rural areas, in this context, can be seen as places to be re-discovered their traditions, their landscapes, their gastronomy, their handicraft, that is to say, their their culture. However, in order to begin a process of local-rural development based on tourist activity, there is a need first to establish an inventory of the potential resources. Case studies were pursued in the country towns of San Antonio, San Juan and Santa Celia, in the province of Entre Rios (Argentina), The locals are descendents of the Germans from the Volga Region (Russia) who came to Argentina in the late nineteenth century. They have maintained traditions and typical folklore through to the present day and therefore present cultural tourism potential. The work is part of an exploratory research process, using primary and secondary resources. A survey and evaluation matrix of the tourist potential were produced as part of the fieldwork. Any further work (community awareness, management financing and promotion/ legislation) requires the previous elaboration of an inventory.
\end{abstract}

Keywords: Cultural tourism; Rural tourism; Cultural heritage; Local development; Argentina. 


\section{Introducción}

A lo largo de la última década se plantea cada vez enfáticamente que el turismo es una actividad que puede contribuir a los procesos de desarrollo local, constituyéndose en un verdadero dinamizador económico y social de una comunidad.

En este marco el objetivo de este trabajo de investigación es plantear que para que pueda efectivizarse un proceso de desarrollo local basado en el turismo, el primer paso consiste en contar con información previa y estudios sobre la situación del territorio. Para ello, se establece la importancia de emplear instrumentos de relevamiento, evaluación y diagnóstico que permitan conocer si un sitio ó localidad posee verdaderamente un determinado potencial para el desarrollo turístico que justifique la realización de determinadas acciones e intervenciones.

Existen algunos instrumentos y técnicas, que a partir de su aplicación permiten tomar decisiones más ajustadas sobre las posibilidades de desarrollo turístico de un lugar. Ciertos aspectos básicos que pueden ayudar en este análisis, son por ejemplo: analizar las características geográficas y demográficas del lugar, conocer la historia laboral y productiva de la zona, la infraestructura y servicios básicos y generales con que cuenta la localidad, los aspectos relativos a la gestión y desarrollo del turismo (si los hubiera), la disponibilidad de atractivos turísticos culturales o naturales, la existencia de organismos públicos ó privados vinculados a la actividad turística, la legislación o normativa que regula al sector, la accesibilidad hasta el lugar, la existencia de servicios relacionados con la atención al visitante (alojamiento, gastronomía, información, actividades recreativas, señalización etc.), la disponibilidad de recursos humanos capacitados, entre otros aspectos.

Asimismo, se entiende que para este tipo de evaluación resulta importante conocer las características y motivaciones de los visitantes que llegan hasta el lugar o a una zona cercana, y por supuesto también considerar el contexto regional, lo cual permite sopesar las posibilidades de cooperación (o competencia) con otros sitios o destinos próximos.

Evaluar todos estos aspectos puede otorgar mayor sustentabilidad al tener un panorama real de las características y de las especificidades del territorio, evitar el sobredimensionamiento de futuros emprendimientos, como así también impedir o minimizar actividades o intervenciones relacionadas con el turismo que puedan afectar el medio ambiente o la calidad de vida de los residentes.

Es decir, si bien el turismo puede ser el incentivo para el desarrollo local de un gran número de pequeñas localidades ó zonas rurales al constituirse en una actividad que dinamiza las actividades económicas tradicionales y valoriza las particularidades de la cultura local, tiene que ser previamente evaluado, ya que frecuentemente se depositan en esta actividad grandes expectativas que muchas veces pueden conducir a la frustración y al fracaso (Leader-Observatorio Europeo, 1997; Camou, 2010; Scalise, J., 2012; OIT-CIF, 2015 $)$.

Para ello, este trabajo tomó como estudio de caso tres aldeas ${ }^{2}$ rurales ubicadas en la provincia de Entre Ríos, Argentina: Aldea San Antonio, Aldea San Juan y Aldea Santa Celia.

En ellas predominan descendientes de alemanes del Volga y poseen un rico patrimonio cultural. Asimismo, se encuentran cercanas a un centro turístico de importancia a nivel nacional, como es la ciudad de Gualeguaychú, dentro del área de influencia del Corredor turístico del río Uruguay. Por otra parte, existe la intención de uno de los gobiernos municipales de complementar las actividades productivas del territorio incorporando también el turismo.

De esta manera, a partir de la aplicación de determinados instrumentos para el relevamiento y diagnóstico de las aldeas, el resultado esperado es conocer de manera más objetiva las posibilidades para el desarrollo del turismo en las mismas basado en el patrimonio cultural.

\section{Marco teórico. Turismo y desarrollo local}

En la actualidad, es cada vez más frecuente hablar de desarrollo local basado en el turismo, y son muchos los territorios que están protagonizando procesos de recuperación y expansión económica gracias a la evolución que está experimentando este sector. Tal es el caso del Departamento del Meta en Colombia, la Isla de Chiloe en Chile, o el Valle de Colca en Perú, por solo nombrar algunos ejemplos (GIZ-Programa de Cooperación Alemana, 2016; Baeza y Correa, 2011; Hernández Asensio, 2009).

$\mathrm{Al}$ respecto, diversos documentos y declaraciones internacionales establecen que el turismo es una actividad que contribuye al desarrollo local ${ }^{3}$ y puede constituirse en un instrumento de inclusión y dinamización social y económica de un territorio. Estos documentos postulan que el sector promueve 
la creación de empleo, la generación de nuevas actividades productivas, y en el caso particular de los países en desarrollo, colabora en la atenuación de la pobreza (OMT-OEA, 2018; OMT, 2018; OMT-PNUD, 2017; ONU, 2012). En particular, la Organización Internacional del Trabajo establece que es cada vez más frecuente hablar de desarrollo local basado en el turismo, y son muchos los territorios que están protagonizando procesos de recuperación y expansión económica debido a la evolución que está experimentando este sector. No obstante, si esta actividad es deficientemente planificada, y si no se tiene en cuenta la intervención de los actores locales en las distintas fases del proceso, puede acarrear ciertos riesgos para el desarrollo territorial. Respeto por el medio ambiente y la cultura local, son las condiciones indispensables para hacer del turismo una actividad sostenible, pero no exclusivamente. El consenso y el acuerdo local son aspectos esenciales que deben ser impulsados entre todos, para que el desarrollo local sea una realidad consolidable en el mediano y largo plazo (OIT-CIF, 2004).

En esta línea, otros autores plantean que el desarrollo local es un proceso controlado por los actores del propio territorio, donde resultan fundamentales las capacidades locales, como por ejemplo, la gestión, la organización, la articulación, el diálogo, el consenso, la confianza, la creación, la innovación, el emprendimiento; y donde es particularmente importante la capacidad de gestionar los propios recursos, sabiendo aprovechar estratégicamente los recursos externos (Madoery, 2008, Fundación Demuca, 2009).

Para Vázquez Barquero (1998 y 2009) el desarrollo local es un proceso de crecimiento de la actividad económica y cambio de la estructura productiva, y por lo tanto promueve políticas de transferencia de recursos de las actividades tradicionales a las modernas, entre ellas, el turismo. En particular, el crecimiento de la renta y los fuertes cambios en la demanda han provocado la diversificación de la producción tanto en las áreas urbanas como en las rurales, por lo que el desarrollo de la actividad turística en Latinoamérica muestra cómo los cambios en la demanda internacional plantean la necesidad de introducir continuamente innovaciones que fortalezcan la competitividad de los territorios. Reforzando lo anterior, Wallingre (2017) indica que, en las últimas décadas uno de los enfoques del turismo se sustenta en los fundamentos y características del desarrollo endógeno o local, el cual es de tendencia incluyente y "procura el desarrollo integral armonizando el empleo del territorio y el patrimonio, con la implementación de infraestructuras y servicios que permitan concertar el estándar de vida requerido por la comunidad local con la lógica de la rentabilidad (mayor porcentual de producción y comercialización de bienes y servicios turísticos por parte de los residentes)".

En base a las consideraciones anteriores, se puede establecer que el turismo es una actividad económica que combina recursos endógenos y exógenos, los cuales correctamente articulados, proponen un conjunto de beneficios sociales, económicos, ambientales y culturales. No obstante, si no es debidamente planificado y gestionado puede producir efectos negativos para el territorio. En este sentido es importante tener en cuenta que el turismo precisa de un método que haga que los esfuerzos invertidos y los recursos utilizados, tanto propios como externos al territorio, sean optimizados al máximo. Por lo tanto, el primer paso en la elaboración de estrategias de desarrollo local es realizar un diagnóstico de la zona o el territorio, analizando los problemas, las necesidades, y teniendo un conocimiento de los recursos con los que se puede contar. De esta manera, sobre la base de estos estudios, se podrán tomar decisiones más acertadas.

En líneas generales, todos los territorios - tanto las áreas rurales como las ciudades - poseen en mayor o menor medida, un conjunto particular de recursos humanos, naturales y físicos; un patrimonio histórico y cultural; infraestructuras de soporte; un sistema productivo, conocimientos técnicos, capacidad empresarial, estructura social y política, y formas de organización y relación, entre otros. Estos recursos otorgan un potencial que es la base para responder a los retos que presenta el aumento de la competitividad, la integración, la adaptación de los procesos productivos y organizativos requeridos por las nuevas condiciones de la dinámica económica nacional e internacional. A partir del conocimiento de estos recursos, en un momento histórico concreto, una comunidad puede encontrar ideas y proyectos que le permitan producir bienes y servicios y así articular nuevas estrategias e iniciativas locales (Madoery, 2008; Vazquez Barquero, 2009).

Considerando lo anterior, es importante destacar que aquellos territorios que deseen encarar un proceso de desarrollo local basado en el turismo tienen ante todo que conocer los recursos existentes y realizar un diagnóstico de los mismos. De esta manera, a partir de la evaluación de estos recursos desde la perspectiva turística, es posible conocer todo aquello que muchas veces la propia comunidad no sabe que posee, o desconoce el estado actual en que se encuentra. La identificación, diagnóstico y valoración de los componentes del sistema turístico constituye la primera etapa para el desarrollo y la gestión de un territorio. Tener un claro panorama del estado de situación de partida, permitirá una mejor organización de las acciones a seguir, especialmente en la selección y priorización de atractivos 
para su puesta en valor, la ampliación o mejora de la oferta de servicios e infraestructuras, la creación de nuevos "productos", y la definición de un perfil o imagen para el posicionamiento en el mercado (Wallingre, 2014).

\subsection{El turismo basado en el patrimonio cultural en áreas rurales como motor para el desarrollo local}

Distintos documentos de organismos internacionales plantean que el turismo con base en el patrimonio cultural puede constituirse en un instrumento de dinamización socioeconómica de un territorio (OMT, 2018; UNESCO, 2015; OMT, 2013; UNESCO, 2007; ICOMOS, 1999). Al respecto, es importante indicar que el patrimonio cultural ${ }^{4}$ se ha convertido en un atractivo de relevancia para el turismo, $\mathrm{y}$ sus manifestaciones simbólicas y materiales se han ido revalorizando socialmente, ocupando un lugar destacado en la construcción del pensamiento. Actualmente el hombre se acerca cada vez más a los vestigios del pasado y se evidencia un interés creciente por conocer y proteger ese pasado. En esta línea, la valoración del patrimonio cultural constituye uno de los ámbitos más novedosos en las iniciativas locales, ya que supone una visión sobre los recursos culturales e históricos como activos de desarrollo, y por esto permite incorporar elementos de diferenciación tanto en los procesos productivos como en los productos locales (Vereda et al., 2002; Alburquerque, 2007). Con relación a esto, algunos casos relevantes en Argentina son las Rutas del Vino, la Ruta de la Yerba Mate, o el circuito de las capillas galesas en la provincia de Chubut (Boschi y García, 2011; Rodil y Alemany, 2010; Barrera, 2009; Navarro, 2002; Owen y Hughes, 2009).

En este sentido, las áreas rurales, como lugar de vida y de producción, se ven como un mundo a descubrir a través de sus tradiciones, sus paseos, su artesanía, su cultura, y por lo tanto, de la interacción entre la identidad local y aquellos que vienen de otros territorios, nace la posibilidad de construir un valor económico (Fonte, 2009). Cabe indicar que los territorios rurales, los cuales por muchos años fueron identificados como espacios periféricos, relacionados al sector primario de la economía y estructurados en pequeños y medianos núcleos de población, con un modelo de relaciones disperso y difuso, comenzaron a ser redescubiertos. Algunas de las debilidades que los caracterizaban empezaron a revertirse y se produce entonces un rescate, no sólo del entorno geográfico, característico del medio rural, sino también se valorizan las formas de vida, los alimentos y los servicios, como parte de la identidad cultural de las poblaciones. De esta manera, la percepción de la cultural rural fue cambiando hasta convertirse en un espacio factible de ser aprovechado, por ejemplo, a través del turismo (Benedetto, 2007).

$\mathrm{Al}$ respecto, en las últimas décadas se han profundizado las tendencias a nivel mundial en cuanto a la diversificación de los consumos turísticos. Se constata así el surgimiento de una demanda creciente que ha dado origen a nuevos segmentos y nichos de mercado. Dentro de estas nuevas tendencias se evidencia una preferencia por la singularidad, la diferenciación, la autenticidad y los espacios no degradados desde el punto de vista ambiental (MINTUR, 2011).

Sobre la base de estas afirmaciones podría decirse que los destinos turísticos tradicionales y/o saturados han tenido que comenzar a competir con destinos donde es posible acercarse a experiencias caracterizadas por la diferenciación, y el consumo de productos y vivencias exclusivas relacionadas con la tranquilidad y los valores de las culturas locales. Esto permitió el surgimiento de nuevas formas de turismo, como por ejemplo, el turismo cultural en áreas rurales.

\section{Propuesta de metodología para el análisis de un territorio rural desde la perspectiva turística}

Para obtener un análisis más preciso sobre las aldeas rurales San Antonio, San Juan y Santa Celia (provincia de Entre Ríos, Argentina), respecto a su potencialidad turística-cultural, se elaboró un instrumento ó formulario para el relevamiento de las mismas.

Este instrumento constó de cinco secciones, que comprendieron: Sección 1: Datos de la localidad; Sección 2: Características generales de la aldea; Sección 3: Características de la oferta turística actual/ potencial; Sección 4: Gestión y desarrollo del turismo; y Sección 5: Características de la demanda actual. El diseño del formulario se realizó luego de hacer una revisión de las propuestas con relación a las metodologías e instrumentos para el inventario de la oferta turística y el diagnóstico integral de destinos, tanto elaboradas por autores especialistas en la temática, como por distintos organismos nacionales e internacionales (Leno Cerro, 1993; Domínguez de Nakayama, 1994; Leader-Observatorio Europeo, 1997; Valls, 1996; OMT, 1999; Antón Clavé y González Reverté, 2005; Ejarque, 2005; MINTUR-PROFODE, 2012; Wallingre, 2014; Varisco et al., 2014). 
Finalmente, sobre la base de estos autores se tomaron algunos lineamientos del Programa de Fortalecimiento y Estímulo a Destinos Turísticos Emergentes (MINTUR-PROFODE, 2012) y algunos lineamientos del Programa Leader II propuestos en la guía metodológica "Evaluar el potencial turístico de un territorio" orientado a zonas rurales (Leader-Observatorio Europeo, 1997).

El formulario para realizar el relevamiento de las aldeas se completó a través del trabajo de campo, la entrevista a actores locales (fuentes primarias), y la recopilación de información sobre el turismo provincial/regional (fuentes secundarias), durante el período julio 2013-febrero 2015.

Toda la información recopilada a través del instrumento de relevamiento se plasmó luego en una matriz de evaluación del potencial turístico del territorio (Ver ítem 4.2.), donde se identificaron puntos fuertes y débiles, así como oportunidades y riesgos, con base a la información recopilada, analizando y confrontando las características generales y particulares de las aldeas, las características de la oferta turística actual y/o potencial, la gestión y desarrollo del turismo local, la inserción de las aldeas en el contexto regional, la incidencia en las aldeas de destinos turísticos cercanos, y las características de la demanda que llega hasta la región.

En la Figura 1 se sintetiza la metodología general empleada para evaluar el potencial turístico de aldeas rurales.

\section{Figura 1: Metodología para la evaluación preliminar del potencial turístico de las aldeas}

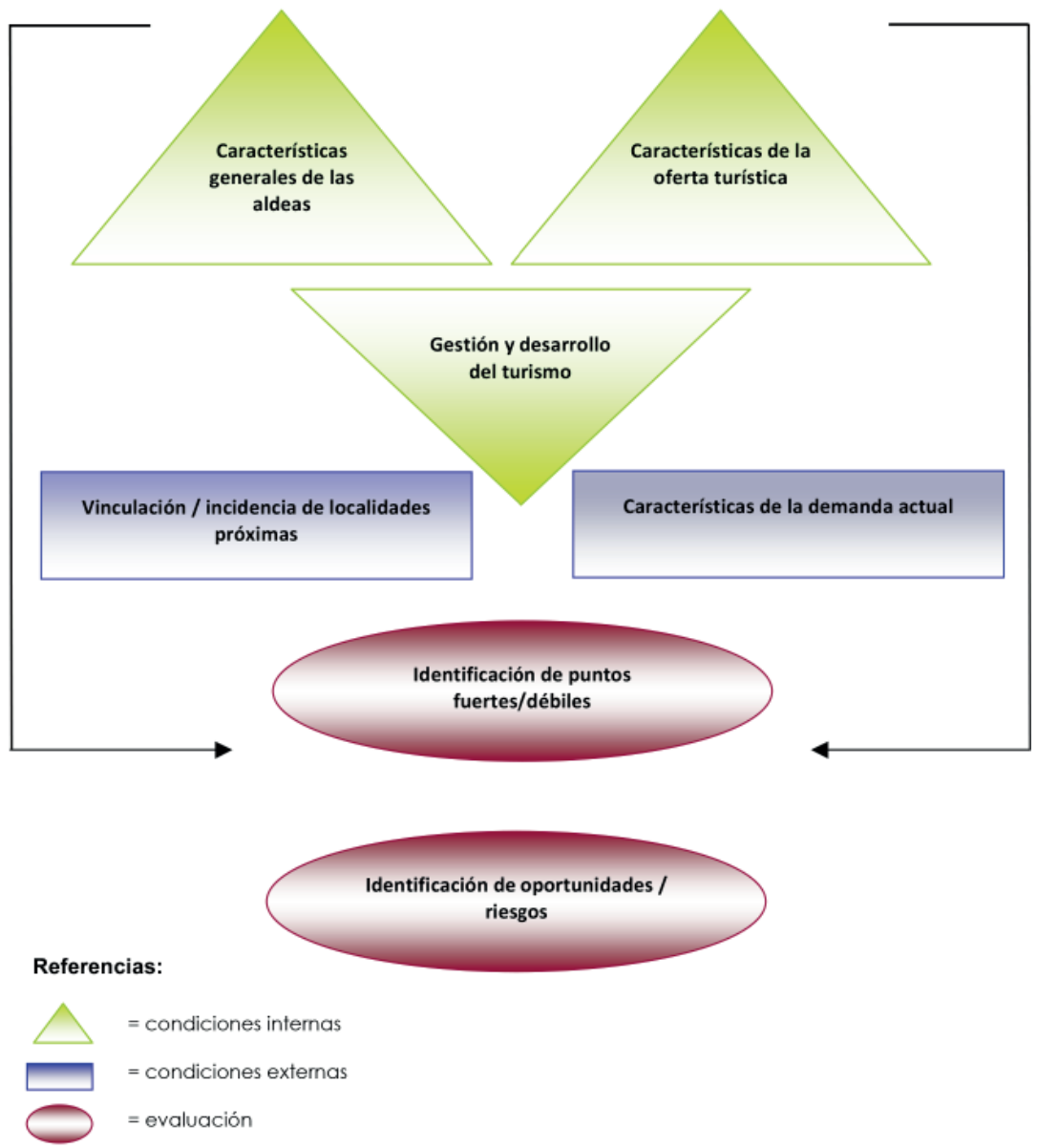

Fuente: Elaboración propia en base a Leader-Observatorio Europeo, 1997. 


\section{Introducción al estudio de caso: Aldeas San Antonio, San Juan y Santa Celia}

Las Aldeas San Antonio, San Juan y Santa Celia se encuentran en el Departamento de Gualeguaychú, provincia de Entre Ríos, aproximadamente a $260 \mathrm{~km}$ de Paraná, capital de la provincia de Entre Ríos, y a $290 \mathrm{~km}$ de Buenos Aires, ciudad capital de Argentina (Figura 2).

\section{Figura 2: Ubicación de las aldeas San Antonio, San Juan y Santa Celia, en el contexto de la provincia de Entre Ríos, Argentina}

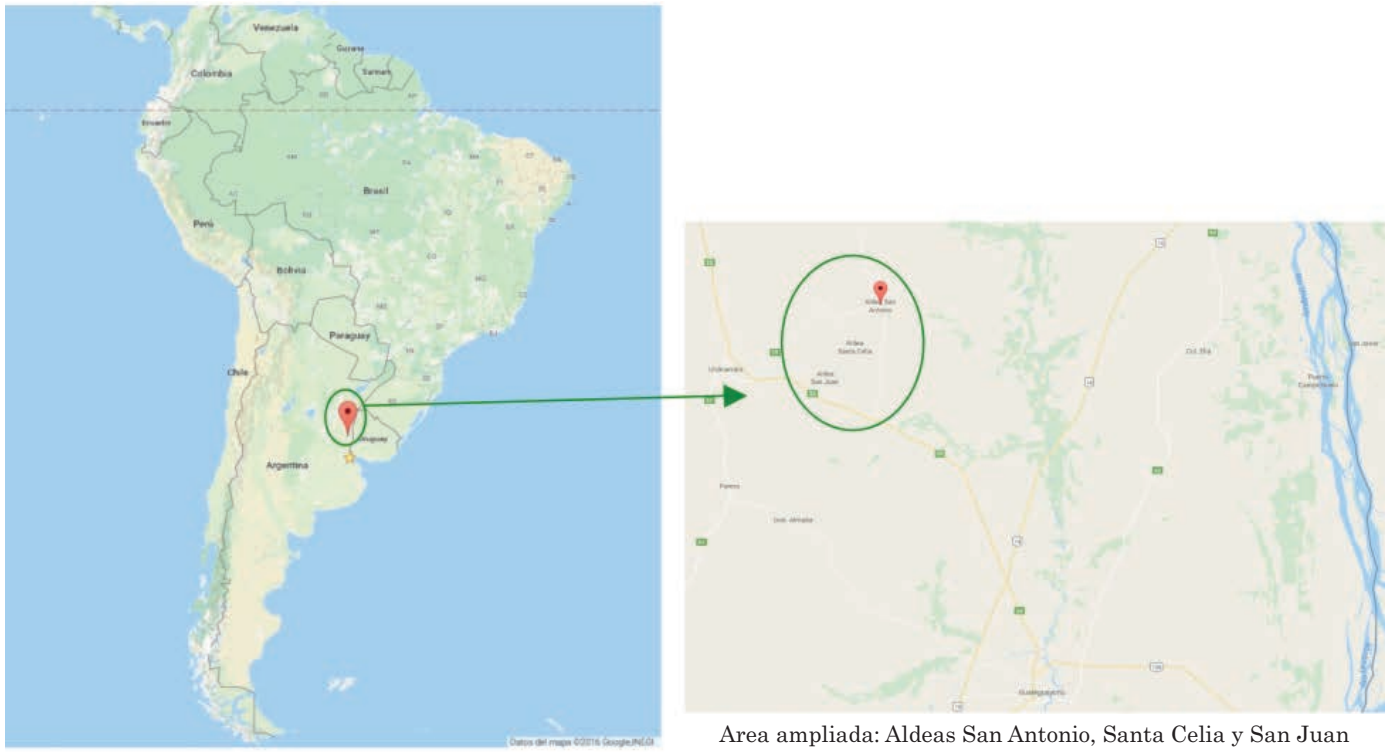

Fuente: Google Maps, https://www.google.com/maps, 2018.

Particularmente, estas aldeas rurales se caracterizan por ser grupos de población muy reducidos ya que no superan - entre las tres localidades - los dos mil habitantes. La base económica de las mismas es la agricultura, y complementariamente la explotación ganadera, la avicultura y la producción lechera. En ellas predominan descendientes de "alemanes del Volga". Poseen un rico legado cultural, con la particularidad de tener iglesias de diversos cultos y conservar una cantidad de tradiciones y costumbres, especialmente relacionadas con la gastronomía, la música, los bailes, la vestimenta y la religión (Toselli y Godoy, 2011).

Para comprender la singularidad de estas aldeas y la riqueza de su patrimonio cultural es necesario conocer la historia de este pueblo, su pasado, sus orígenes, y su llegada a América del Sur, para así entender en esa combinación de aspectos históricos y culturales la identidad que los representa.

Dentro de la colectividad alemana, el grupo denominado los "ruso alemanes" provenientes del Volga constituyen un caso singular de inmigración en la Argentina y ciertamente conocer sobre su historia implica iniciar un recorrido que comienza en Alemania, siguiendo luego por las tierras rusas a orillas del Volga, para finalmente arribar a Argentina a finales del siglo XIX.

Exactamente arriban a la Argentina a finales de 1877, y se establecieron en colonias rurales, en especial en las provincias de Buenos Aires y Entre Ríos. En esta última, se expandieron por todo el territorio, atrayendo a una importantísima corriente de alemanes-rusos. A fines del siglo XIX, constituían el segundo grupo en importancia entre los propietarios extranjeros de explotaciones agropecuarias de la provincia (Firpo, 1998; Flores, 2003).

Actualmente, las tres aldeas alcanzan un total de 2.000 habitantes. Aldea San Antonio, con 1.500 habitantes, es la única aldea que tiene estatus de municipio. Por su parte, Aldea San Juan es un Centro Rural de Población, categoría III (EGES, 2009) y cuenta con 387 habitantes. En tanto, Aldea Santa Celia es un poblado rural en el ejido municipal de San Antonio, municipio del cual depende administrativamente, y no supera los 200 habitantes. 
El eje económico de las aldeas es la actividad agropecuaria, básicamente cultivos de soja, sorgo, maíz y trigo. También ocupa un lugar de importancia la explotación ganadera, los tambos, la avicultura y la apicultura. Y particularmente en Aldea San Juan se localiza una interesante producción artesanal de ladrillo (Comunicación personal, Fuchs, C. 20145; Fuchs, G., 2009).

La distancia entre las aldeas es entre los 8 y $14 \mathrm{~km}$, y cabe destacar, que a $52 \mathrm{~km}$ de estas se ubica la ciudad de Gualeguaychú, un centro turístico de importancia a nivel nacional que se encuentra dentro del Corredor turístico del río Uruguay. Otra ciudad cercana a $25 \mathrm{~km}$ es Urdinarrain, que se encuentra próxima al río Gualeguay, donde está el balneario Arenas. Con relación a los servicios básicos e infraestructura general, Aldea San Antonio es la más equipada de las tres, y cuenta con una provisión adecuada de servicios e infraestructura en relación con su escala (centro de salud, farmacia, seguridad, comunicaciones, bancos, correo, etc.). Estos resultan suficientes para cubrir las necesidades de los habitantes locales, aunque no para recibir una concurrencia masiva de visitantes.

\subsection{Análisis de la oferta turística del área de estudio}

La oferta de servicios y facilidades turísticas ${ }^{6}$ - sólo disponible en Aldea San Antonio - es aún incipiente ya que está conformada por dos hospedajes y dos servicios de comida - y la misma resulta adecuada para el uso de los habitantes locales, viajantes, estudiantes, y eventualmente en el caso de recibir algún grupo de turistas de manera puntual, pero no así para cubrir, por ejemplo, la afluencia generada por la Fiesta del Inmigrante Alemán, donde los turistas tienen que recurrir a alojamientos disponibles en Urdinarrain ó Gualeguaychú.

Aparte del alojamiento y el servicio de restauración, no hay otras prestaciones turísticas (guías, servicios de recreación, agencias de viaje). Tampoco hay venta de productos artesanales locales de manera permanente, a excepción de los puestos ó stands que se instalan durante la Fiesta del Inmigrante Alemán, los cuales ofrecen gastronomía típica, souvenirs, y/o libros de historias de inmigración.

En cuanto a la accesibilidad a las aldeas no hay servicios de ómnibus de media y larga distancia. La localidad más cercana para acceder a este tipo de servicio es Urdinarrain, distante a $25 \mathrm{~km}$ aproximadamente. Solo la existencia de algunos servicios de remise permiten la conexión entre las aldeas en caso de no poseer automóvil particular.

Acerca de los aspectos relativos a la gestión y desarrollo del turismo, Aldea San Antonio es la única localidad que posee un área específica en cultura, turismo y deporte. Si bien no existe una partida presupuestaria ni están establecidas formalmente las responsabilidades de dicha área, como tampoco normativa específica que regule el incipiente sector turístico (alojamiento y restauración), resulta positivo el hecho de que se haya creado un espacio/sector dentro del organigrama municipal, lo cual va sentando el precedente de posicionar esta actividad en la agenda local, como así también seguir la línea de las políticas de turismo provinciales.

Con respecto a la capacitación y formación en turismo resulta de importancia contar con técnicos y profesionales especializados en el tema y formados en localidades cercanas a las aldeas, aunque por el momento no hay posibilidad de inserción laboral en esta actividad hasta tanto no se ofrezcan nuevas condiciones para el desarrollo del turismo.

La promoción y difusión que se realiza - especialmente de la Fiesta del Inmigrante Alemán - se ve reflejada en la participación del municipio de Aldea San Antonio en distintas presentaciones, stands, notas periodísticas y televisivas, tanto en la misma provincia de Entre Ríos como en la Ciudad de Buenos Aires.

Si bien no se dispone de folletería, como tampoco de una oficina de información turística, se brinda atención a los visitantes en la Casa de la Cultura ubicada en la Avenida principal de Aldea San Antonio dentro de los horarios de atención que tienen las dependencias municipales. Vale indicar que el fin de semana de la Fiesta del Inmigrante Alemán, la Casa de la Cultura se encuentra abierta al público.

De las dos localidades turísticas más cercanas, Gualeguaychú ${ }^{7}$ y Urdinarrain ${ }^{8}$, existe mayor vinculación con esta última, especialmente por la proximidad, como también por la posibilidad de difusión de la Fiesta del Inmigrante Alemán en distintos eventos que se realizan en dicha localidad.

Respecto a los circuitos integrados, se promovió durante algunos años la iniciativa de la micro región turística "Pueblos del Sur entrerriano" integrado por más de 10 localidades y poblados rurales, siendo parte de esta integración las tres aldeas. No obstante, a pesar de los esfuerzos para la conformación y sostenimiento de esta micro región turística, y pese al impulso de algunos actores locales por dar continuidad a esta iniciativa, la misma no ha prosperado de acuerdo con lo esperado. 
En cuanto a las características de la demanda actual, se observa que el único perfil aproximado del turista que llega hasta el lugar se puede obtener a través de los datos que proporcionan las localidades de Gualeguaychú y Urdinarrain. Esta demanda se caracteriza por ser un tipo de turismo de mayor afluencia durante la temporada de verano (especialmente en los meses de diciembre a marzo), aunque también en los últimos años se ha registrado una afluencia de visitantes durante Semana Santa, vacaciones de invierno y fines de semana largo, debido a la diversificación de productos en los que ha trabajado particularmente Gualeguaychú, entre ellos termas y ecoturismo.

El lugar de procedencia es mayormente de localidades de Buenos Aires y Ciudad de Buenos Aires; también Santa Fe, Córdoba y de distintas localidades entrerrianas. Predomina el turismo de familias, se informan principalmente por referencia de otras personas o por Internet; y el medio de transporte más utilizado es el automóvil.

Con relación a los atractivos turísticos actuales / potenciales de las aldeashay un rico legado cultural tanto tangible como intangible, reflejado esto en la conservación de objetos y utensilios domésticos y productivos, en las numerosas iglesias y antiguas viviendas de más de cien años, así como en la música, los bailes, la gastronomía y la vestimenta típica. La historia inmigrante ocupa un lugar central en las aldeas, lo cual marca su identidad, su idiosincrasia y le otorga un valor agregado que las diferencia de otras comunidades cercanas.

Es de destacar que los pobladores, reconocen y mantienen vivas sus raíces, las costumbres de la colonia y las tradiciones familiares, nutriendo así la vida cultural y su preservación tanto a través de instituciones locales, como a través de sus fiestas.

$\mathrm{Al}$ respecto se observa que a pesar de haber transcurrido muchos años, Aldea San Antonio aún preserva huellas de su pasado, sobre todo en lo referente a la música, donde muchas personas del pueblo saben ejecutar algún instrumento y se dedican a la música tradicional alemana de sus abuelos (Volksmusik). Existe también una rica tradición en cuanto a la gastronomía típica, sin embargo, no hay un registro de las mismas y esto va pasando de generación en generación por transmisión oral.

Con relación a la arquitectura y las edificaciones existen casas antiguas que aún conservan su construcción original de hace 100 años, pero con remodelaciones. Décadas atrás éstas se caracterizaban por ser construcciones de tipo ladrillera, con una puerta de entrada por el costado (no por el frente), tenían techo a dos aguas con altillo, tres ventanas al norte y la puerta de entrada al sur, protegida por una galería, pero las mismas se fueron modificando con el tiempo y quedan pocas que conservan el estilo original. Dentro de las fiestas locales, se destaca el aniversario de fundación de la Aldea que se realiza el último fin de semana de febrero de cada año, y ese mismo día se festeja la Fiesta del Inmigrante Alemán (Figura 3).

Figura 3: Aniversario del Pueblo y Fiesta del Inmigrante Alemán
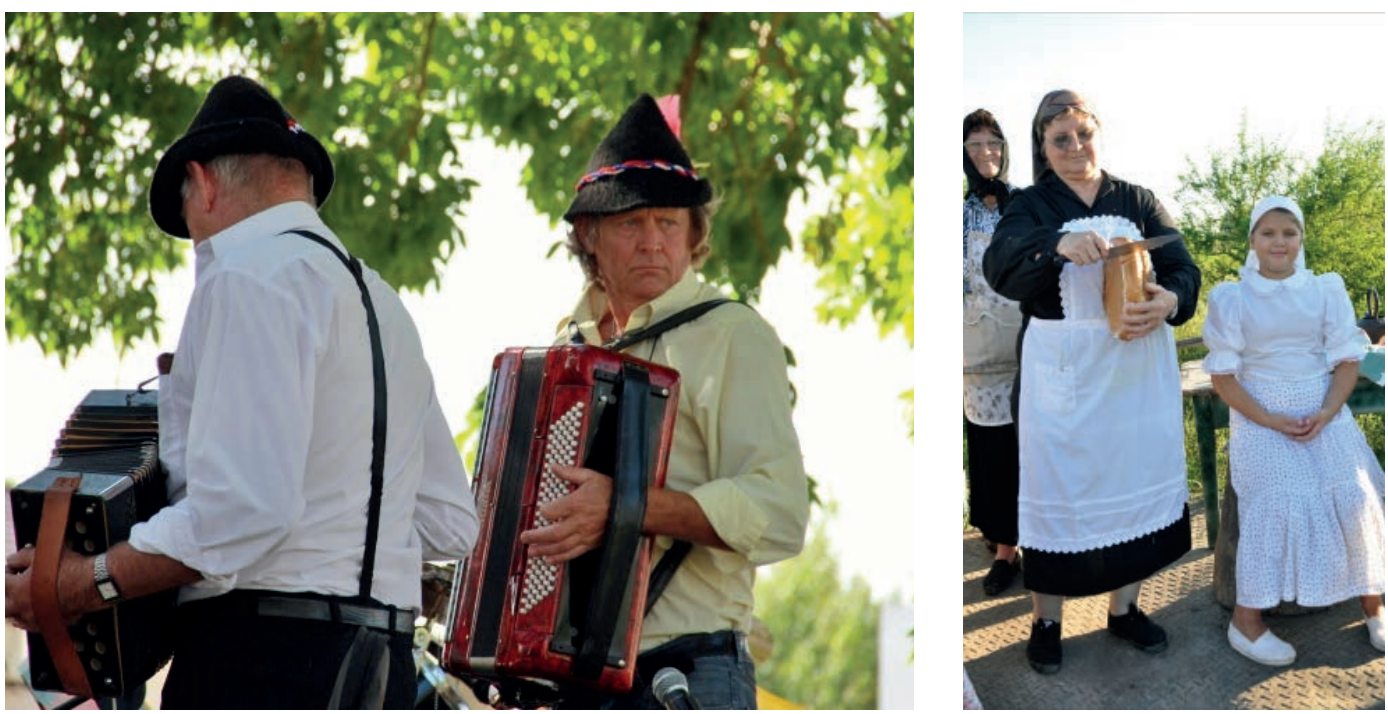

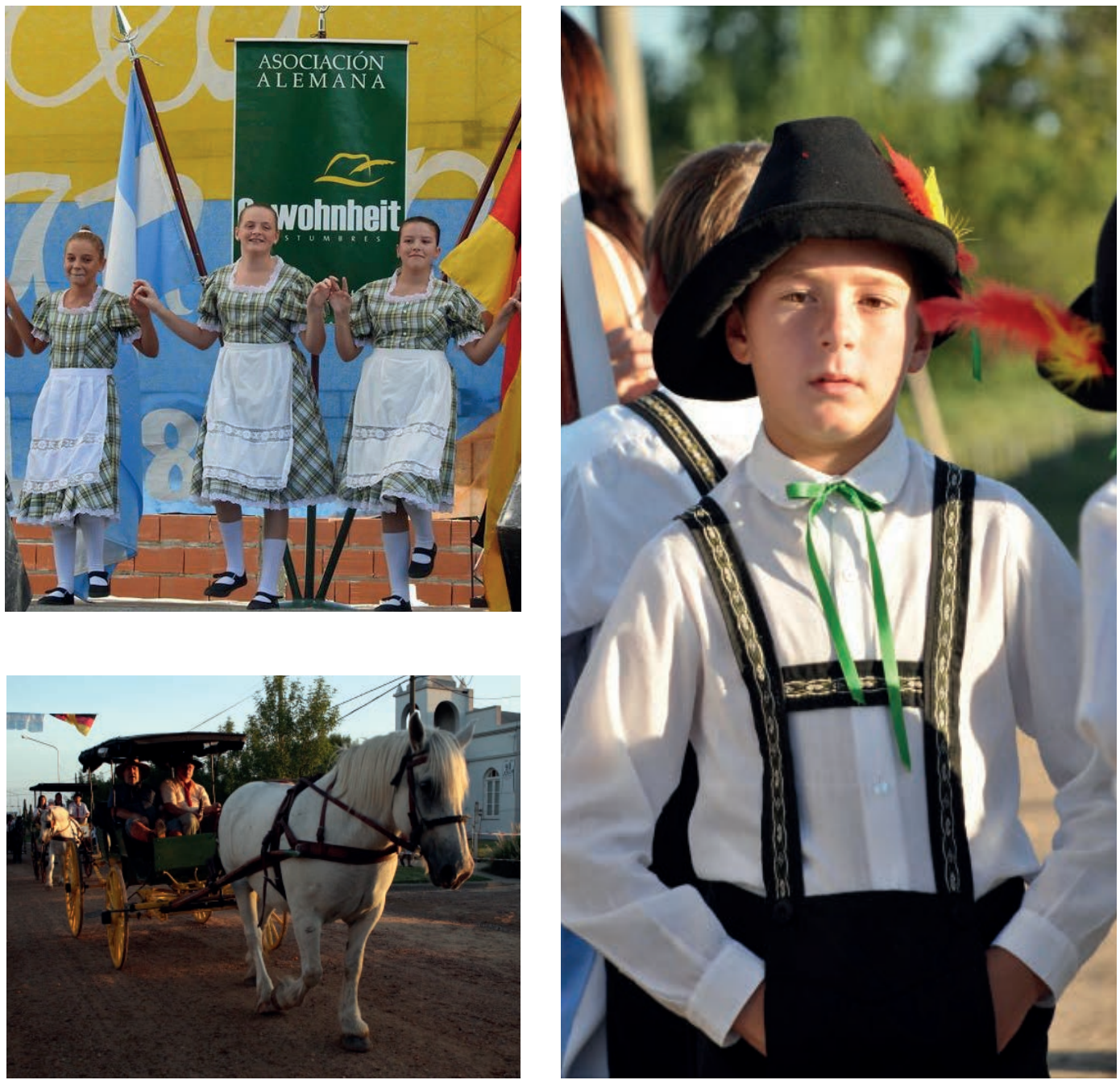

Fotos: Ferreyra, G., Prensa Aldea San Antonio, 2013, 2017 y 2018.

En particular, esta fiesta realizada desde hace más de dos décadas consecutivas constituye la máxima expresión de la identidad de Aldea San Antonio, y en la cual participan también las Aldeas San Juan y Santa Celia. Este evento es sin dudas el principal atractivo turístico a partir del cual actualmente se produce la mayor afluencia de visitantes hasta el lugar. Allí las distintas expresiones culturales vinculadas con la gastronomía, la música, el baile, la vestimenta típica, las costumbres y usos de antaño, se resignifican en toda su magnitud, permitiendo su transmisión a las nuevas generaciones y afianzando la identidad cultural de la comunidad.

Todo el pueblo y las casas se adornan con banderas argentinas y alemanas para esa ocasión. En particular, los festejos inician desde la mañana en la plaza frente al edificio municipal, donde hay stands de artesanías, comidas - prode de cerdo, krau pirök, dinne kuchen ó kreppel $^{10}$ - y bebidas típicas alemanas - como el quast ${ }^{11}$ -. También hay orquestas en vivo, actuaciones del ballet alemán, paseos gratis en carro ruso y un museo interactivo ${ }^{12}$ al aire libre que muestra distintos elementos domésticos que utilizaban las antiguas generaciones.

Durante la tarde comienza el desfile típico alemán por las calles de la aldea, con carrozas representativas, delegaciones de ballets, "carros rusos", y música alemana en vivo.

Cabe indicar que la religiosidad es muy importante en las aldeas. En ellas se encuentran ocho templos o iglesias de diversos cultos, todas en muy buen estado de conservación (Figuras 4). 
Figura 4: Iglesias de Aldea San Antonio, San Juan y Santa Celia
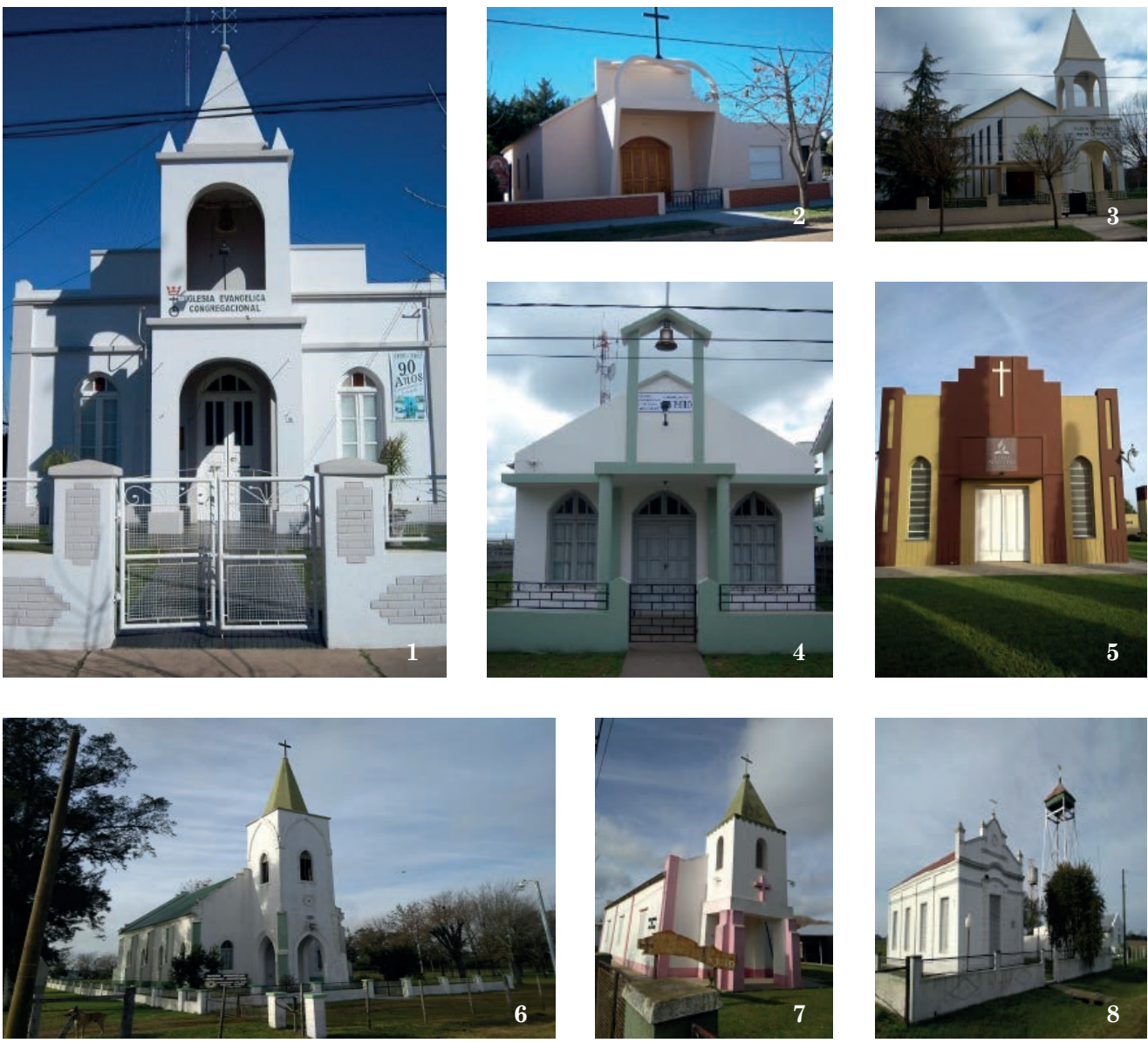

Detalle: Aldea San Antonio: 1) Iglesia Evangélica Congregacional; 2) Capilla Católica San Antonio de Padua; 3) Iglesia Evangélica del Río de la Plata; 4) Iglesia Evangélica Luterana; 5) Templo Adventista.

Aldea San Juan: 6) Iglesia Evangélica Luterana; 7) Iglesia Evangélica del Río de la Plata. Aldea Santa Celia: 8) Iglesia Evangélica Luterana del Río de la Plata. Fotos: Toselli, C., 2013, 2014 y 2018.

Acerca de las expresiones culturales relevantes, algunas instituciones que ayudan a transmitirlas a las nuevas generaciones son la Asociación Alemana "Gewohnheit" en Aldea San Antonio. En la misma actualmente se realizan eventos y ensayos de danzas alemanas como la Polka Tradicional, Polka del Sapito, la Nach Lindenau Krauss y la Danza Voladora. Asimismo, participan en la Fiesta del Inmigrante Alemán en el desfile tradicional con trajes típicos, presentación de bailes y comidas tradicionales (Kindsvater, G., 2014, comunicación personal13).

En Aldea San Juan se ha conservado el dialecto alemán, algunas comidas típicas y la música. En las fiestas que se realizan se escucha música alemana, especialmente polkas. Además, se encuentra la Filial Unser Dorf, institución que aglutina a los descendientes fundadores del pueblo y ayuda a preservar la cultura local. También participa en los desfiles de la Fiesta del Inmigrante Alemán de Aldea San Antonio.

\subsection{Matriz de evaluación del potencial turístico de las aldeas}

De acuerdo con el análisis desarrollado hasta aquí, se presenta a continuación una matriz de evaluación del potencial turístico en base a los componentes relevados el instrumento de relevamiento (Figura 5). Para ello, se analizan desde la perspectiva interna, puntos fuertes y débiles; y desde la perspectiva externa, oportunidades y riesgos para el desarrollo del turismo en estas aldeas rurales. 


\section{Figura 5: Matriz de evaluación del potencial turístico de las aldeas}

\begin{tabular}{|c|c|}
\hline Puntos fuertes & Puntos débiles \\
\hline \multicolumn{2}{|l|}{ Respecto a las características y servicios generales de las aldeas } \\
\hline $\begin{array}{l}\text { - Localización en el área de influencia del Corredor turístico del río } \\
\text { Uruguay. } \\
\text { - Existencia en Aldea San Antonio de servicios básicos generales } \\
\text { (educación, red de agua potable, red de gas, etc.). } \\
\text { - Proximidad a uno de los principales centros emisores de turistas } \\
\text { del país, como son la Ciudad de Buenos Aires y Gran Buenos Aires. }\end{array}$ & $\begin{array}{l}\text { Falta de disponibilidad de gran cantidad de servicios } \\
\text { básicos generales en las Aldeas San Juan y Santa Celia } \\
\text { (comunicación, transporte, red de agua potable, red de } \\
\text { gas, etc.) }\end{array}$ \\
\hline
\end{tabular}

Respecto a la oferta turística actual/potencial (atractivos culturales/naturales; accesibilidad y medios de transporte; servicios turísticos)

- Disponibilidad de un patrimonio cultural tangible que se visualiza en la existencia de diversas iglesias y viviendas antiguas de más de cien años.

- Existencia de un rico patrimonio cultural intangible relacionado con el legado cultural inmigrante, la historia, la religión, la gastronomía, la música, el baile y la vestimenta típica.

- Existencia de un atractivo que genera llegada de visitantes de manera espontánea a partir de un recurso propio y genuino como es la Fiesta del Inmigrante Alemán en Aldea San Antonio.

- Existencia de organismos de la sociedad civil que mantienen vigentes las tradiciones y costumbres de los inmigrantes del Volga.

- Inexistencia de un museo local que permita difundir a los visitantes y transmitir a las nuevas generaciones aspectos de la cultura inmigrante que caracteriza a las aldeas.

- Falta de registro de las expresiones culturales tangibles e intangibles.

- Las asociaciones locales no mantienen vínculos con los países de origen lo cual puede incidir en el sostenimiento y continuidad de estas instituciones.

- Dificultades con relación a los medios de transporte públicos que llegan hasta el lugar.

- Escasa disponibilidad e incipiente calidad de los servicios de alojamiento, gastronomía y otros servicios turísticos.

- Falta de cartelería descriptiva que identifique los principales sitios de las aldeas, especialmente las iglesias.

\section{Respecto a la gestión y desarrollo del turismo a nivel local}

- Creación de un área específica de turismo en Aldea San Antonio dentro del organigrama municipal, y posicionamiento de la actividad en la agenda de la administración local.

- Disponibilidad de un sitio web municipal (Aldea San Antonio) que difunde especialmente la Fiesta del Inmigrante Alemán.

- No se han realizado inventarios de atractivos turísticos.

- No hay planes de desarrollo y/ o de marketing turístico.

- No existe normativa vinculada a la protección del patrimonio natural y cultural, ni tampoco un registro de los bienes culturales tangibles intangibles disponible en las aldeas.

- Existencia de escasa folletería del destino y falta de difusión en el sitio web institucional de distintos sitios que pueden ser visitados en las aldeas, especialmente iglesias y monumentos.

Respecto a las características de la demanda turística

- Aumento y registro de la cantidad de visitantes a la Fiesta del Inmigrante Alemán realizada durante los últimos tres años.
- Falta de información estadística fehaciente con relación a las características de los turistas que llegan hasta las aldeas a lo largo del año.

\begin{tabular}{|c|c|}
\hline Oportunidades & Riesgos \\
\hline \multicolumn{2}{|l|}{ Respecto a la gestión y desarrollo del turismo } \\
\hline $\begin{array}{l}\text { Posibilidad de incorporación de recursos humanos formados en } \\
\text { turismo y hotelería, capacitados en localidades cercanas. } \\
\text { - Cercanía de las aldeas a dos localidades con afluencia turística } \\
\text { como son Gualeguaychú y Urdinarrain. } \\
\text { - Oportunidad de difusión de la Fiesta del Inmigrante Alemán y las } \\
\text { costumbres de Aldea San Antonio en las localidades cercanas que } \\
\text { tienen afluencia turística. }\end{array}$ & $\begin{array}{l}\text { Débil articulación/comunicación, desde la perspectiva } \\
\text { turística, entre las aldeas y los destinos turísticos } \\
\text { cercanos más importantes. }\end{array}$ \\
\hline \multicolumn{2}{|l|}{ Respecto a las características de la demanda actual } \\
\hline $\begin{array}{l}\text { - Afluencia masiva de turismo durante la temporada de verano, } \\
\text { especialmente a Gualeguaychú. } \\
\text { Visitantes que llegan a Gualeguaychú que utilizan como principal } \\
\text { medio de transporte el automóvil, motivo por el cual pueden } \\
\text { trasladarse con mayor facilidad hasta las aldeas. } \\
\text { - Permanencia en el destino Gualeguaychú entre } 3 \text { y } 5 \text { días, lo cual } \\
\text { posibilita la visita a otros sitios cercanos, como por ejemplo, las } \\
\text { aldeas. }\end{array}$ & \\
\hline \multicolumn{2}{|l|}{ Respecto a aspectos relevados del turismo provincial y regional } \\
\hline $\begin{array}{l}\text { Aumento en las demandas turísticas orientadas al turismo } \\
\text { cultural y rural, y nuevas tendencias que reflejan una preferencia } \\
\text { por la autenticidad y los espacios no degradados. } \\
\text { La tranquilidad del lugar y la amabilidad de su gente constituye } \\
\text { un atractivo de acuerdo a las nuevas tendencias en turismo. }\end{array}$ & $\begin{array}{l}\text { Difuso apoyo extra local con relación a la } \\
\text { implementación de programas de preservación y } \\
\text { normativa del patrimonio cultural. } \\
\text { Existencia de productos similares con más } \\
\text { posibilidades de desarrollo en la misma provincia de } \\
\text { Entre Ríos, como son las aldeas de alemanes del Volga } \\
\text { en la zona del Paraná, Entre Ríos. }\end{array}$ \\
\hline
\end{tabular}




\section{Recomendaciones para el desarrollo del turismo en las aldeas}

En particular, las aldeas rurales objeto de estudio de este trabajo, cuentan con atractivos turísticos actuales y potenciales suficientes para diseñar una propuesta de desarrollo turístico. A partir del relevamiento preliminar realizado, se constata que poseen un singular patrimonio cultural tanto tangible como intangible de raíces inmigrantes, sobre el cual pueden encontrar su apoyo para el desarrollo del turismo, particularmente basado en la existencia de bienes culturales tangibles (iglesias, viviendas, monumentos, elementos y objetos de uso doméstico y productivo), y de bienes culturales intangibles (historias de inmigración, creencias religiosas, gastronomía, música, vestimenta).

Cabe destacar que la historia del largo recorrido de los alemanes del Volga hasta llegar a estas tierras, el número de iglesias bien preservadas de distintos cultos que conviven armoniosamente en poblados tan pequeños, así como las tradiciones y costumbres inmigrantes heredadas que a más de 120 años de su fundación se conservan casi intactas, constituyen un atractivo potencial que sumado a la tranquilidad del lugar y la amabilidad de los habitantes, pueden constituir un producto de turismo cultural en un espacio rural factible de enmarcarse dentro de las tendencias turísticas actuales.

Es a partir del análisis de resultados y la matriz de evaluación del potencial turístico de las aldeas desarrollados anteriormente, surgen distintas recomendaciones, como por ejemplo, mejorar aspectos de accesibilidad al sitio (medios de transporte), desarrollar nuevos productos, fortalecer la integración con localidades cercanas, y especialmente, poner en valor el patrimonio cultural tangible e intangible de las aldeas.

Con relación a esto último, resulta primordial la realización de inventarios de atractivos turísticos, especialmente aquellos vinculados con el patrimonio cultural. Este es un tema que merece especial atención, y se entiende que existen las condiciones para ello, ya que el área a cargo de estos temas en Aldea San Antonio vincula turismo y cultura dentro del mismo sector municipal.

En este contexto, sería entonces prioritario impulsar un relevamiento, registro e inventario del patrimonio cultural mueble e inmueble (viviendas más antiguas, iglesias, instrumentos de producción y labranza, utensilios domésticos, trajes típicos, etc.), como así también del patrimonio cultural intangible (historias de la inmigración, personajes más relevantes de la comunidad, tradiciones, usos y costumbres, creencias, religión, música y danzas típicas, recetas, modos de producción, etc.).

Disponer de una información más detallada de estos aspectos permitiría impulsar distintas acciones, tales como:

- Conocer en profundidad cuestiones relacionadas con el patrimonio cultural local para la difusión entre la propia comunidad, especialmente pensando en el legado para las futuras generaciones.

- Identificar el grado de deterioro de algunos edificios, y así implementar un marco normativo que protegiera estos bienes antes de que el paso del tiempo sea irreversible, como así también la posibilidad de solicitar financiamiento ante organismos provinciales, nacionales o fundaciones privadas que permitieran recuperar o preservar este patrimonio cultural local.

- Detectar nuevos atractivos que puestos en valor faciliten la ampliación de la oferta turística. Esto permitiría, por ejemplo,elaborar un circuito turístico-cultural integrando las tres aldeas, incorporar información en cartelería explicativa, en folletos, mapas, en el sitio Web municipal, y/o en el portal turístico de la provincia de Entre Ríos.

- Analizar junto a la comunidad, posibles emprendimientos a partir del rescate y puesta en valor de dicho patrimonio relacionado, por ejemplo, con la elaboración de artesanías, la elaboración de comidas y bebidas tradicionales, el rescate de la música, canciones y bailes tradicionales para realizar presentaciones, etc. Todo esto, además de contribuir a la preservación de la identidad local, podría generar nuevas actividades productivas.

- Considerar también la posibilidad de reabrir el museo local ó una pequeña sala de exposición en Aldea San Antonio, donde se exhiban los objetos domésticos, elementos e instrumentos de labranza o de producción, que se muestran durante la Fiesta del Inmigrante Alemán. Esto, además de estar disponible para la comunidad local a modo de mantener viva la memoria y transmitir la historia a las nuevas generaciones, podría abrirse en las fechas de mayor afluencia de visitantes, donde a partir del cobro de una entrada y/o la venta de souvenirs ó artesanías de producción local, podrían otorgarle sustentabilidad a esta iniciativa.

En síntesis, la elaboración de un relevamiento, registro e inventario específico y detallado de los bienes culturales locales existentes, permitiría detectar posibles atractivos o emprendimientos turísticos. Por 
lo tanto, sobre la base de la Fiesta del Inmigrante Alemán, se podría pensar en un desarrollo, donde de manera concéntrica se agreguen otras actividades o sitios en base al patrimonio tangible e intangible disponible, como por ejemplo se puede observar en la Figura 6.

\section{Figura 6: Desarrollo concéntrico de posibles atractivos turísticos en las aldeas sobre la base de la Fiesta del Inmigrante Alemán}

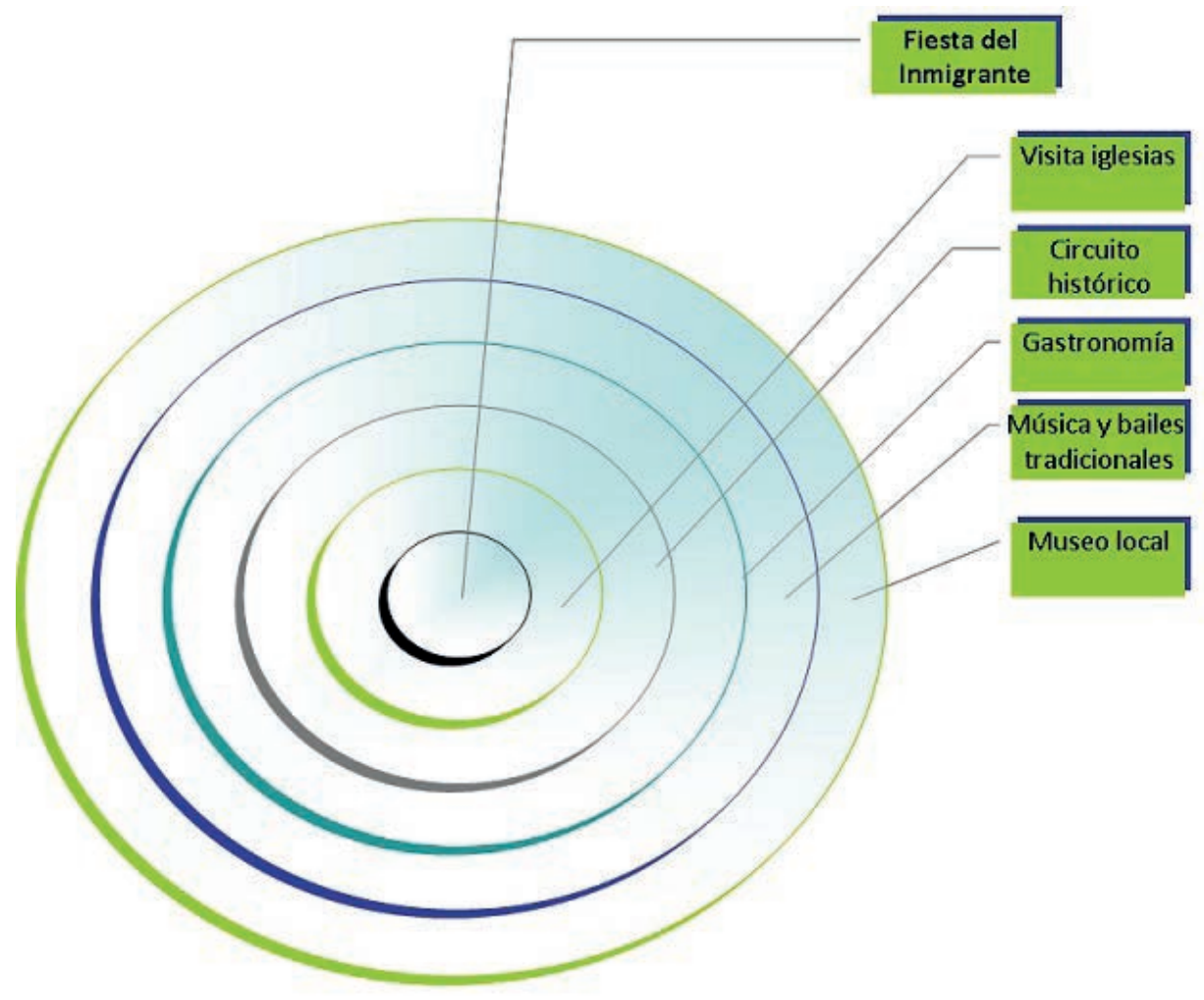

Otro aspecto que considerar es la fecha en la que tiene lugar la Fiesta del Inmigrante Alemán, la cual tiene lugar a finales del mes de febrero, en coincidencia con la etapa de mayor arribo de turistas hacia las localidades de Gualeguaychú y Urdinarrain (temporada de playa, río y carnavales). Para ello, sería importante continuar o fortalecer el acercamiento con estas localidades ya que las mismas pueden constituirse en centros de promoción y difusión de los atractivos existentes en las aldeas.

A partir de estas localidades se podría aprovechar la afluencia de visitantes que llegan hasta allí para tratar de captar un porcentaje interesado en productos orientados al turismo cultural y/o rural. En este sentido resulta de utilidad contar con información cuali y cuantitativa sobre los turistas actuales para pensar en el desarrollo de servicios o productos orientados al perfil de dicha demanda.

Sobre este tema, es interesante enfatizar que un municipio o localidad aislada, no puede mantenerse al margen de lo que ocurre a su alrededor. En el plano turístico y desde la perspectiva del desarrollo local, sumar recursos, infraestructuras, servicios, etc., potencia enormemente las posibilidades de construir un destino con oportunidad de ser integrado en los circuitos ya existentes y posicionados en el mercado turístico, como así también se aumenta la capacidad de respuesta ante posibles eventualidades que puedan surgir a partir del desarrollo de esta actividad (OIT-CIF, 2015 ${ }^{\mathrm{b}}$ ).

Aldea San Antonio es de las tres aldeas la única que cuenta con condiciones incipientes pero promisorias para el desarrollo del turismo, ya que posee un área de gestión específica, está instalada la actividad en la agenda municipal, y existen en la localidad algunos pequeños emprendimientos en materia turística. 
Asimismo, la Fiesta del Inmigrante Alemán que se desarrolla anualmente, constituye el atractivo principal a partir del cual se movilizan turistas y visitantes hasta el lugar. Se considera que en base a esta fiesta podrían apoyarse otros recursos o productos de manera concéntrica, los cuales se podrían "crear" ó "recrear" sustentados en un relevamiento e inventario del patrimonio tangible e intangible.

Otra consideración que surgen a la luz de esta investigación es que claramente la base productiva de las aldeas se focaliza en la actividad agropecuaria, por tanto, se entiende que en caso de desarrollar el turismo, esta sería - al menos en un primer momento - una actividad complementaria.

Por otra parte, hay que tener en cuenta que existen políticas de desarrollo turístico a nivel provincial que representan una oportunidad, como por ejemplo, la vinculación de pequeñas localidades con otras de mayor envergadura, considerando que las primeras cuentan con recursos culturales y naturales que pueden ser incluidos como complemento de destinos turísticos de mayor desarrollo, dándole al conjunto de estos espacios, la diversidad necesaria para hacerlos más completos y atractivos.

Con relación a estas acciones provinciales es importante tener en cuenta lo que plantea Alburquerque (2009), en cuanto a que el desarrollo local no sólo debe basarse en los recursos propios, sino también en la capacidad local de aprovechar las oportunidades existentes, tanto endógenas como exógenas. Asimismo, este autor plantea que si bien el desarrollo local tiene un enfoque ascendente (abajo-arriba), también son importantes las actuaciones y políticas de carácter descendente (arriba-abajo), otorgando relevancia a la coordinación entre los diferentes niveles de las administraciones públicas ya sea local, regional, provincial y nacional.

Siguiendo esta línea de pensamiento, se observa que faltaría fortalecer el trabajo conjunto entre las localidades cercanas ya que en el marco del desarrollo local resulta fundamental trabajar el tema de alianzas y asociatividad, particularmente en turismo, donde un elemento aislado tiene menor capacidad de sostenibilidad en el tiempo, especialmente ante la multiplicidad de destinos ó productos que van surgiendo cada año.

Por último, en todo este contexto no hay que olvidar que, aunque se profundizara en estudios más completos de evaluación del potencial turístico, es importante la opinión de la comunidad local.

En base a las consultas realizadas a distintos actores locales, a priori pareciera existir una división entre los habitantes locales con relación a otorgar mayor impulso a la actividad turística. En particular, en Aldea San Antonio existe un sector de la comunidad más reticente al desarrollo turístico, en tanto otro sector está abierto a las oportunidades que brinda el turismo, considerando especialmente el orgullo de dar a conocer y difundir la cultura inmigrante de estas aldeas. De allí que sería fundamental por parte de las autoridades locales en caso de querer llevar adelante un proceso de desarrollo turístico, realizar un sondeo de percepción entre los residentes de las aldeas, especialmente para dar apoyo y sostenibilidad en el tiempo a cualquier acción que se emprenda en la materia.

Finalmente, indicar que si se dieran las condiciones propicias para encarar acciones en materia turística, su desarrollo no debería plantearse solamente desde la perspectiva de la diversificación económica-productiva, sino también desde la perspectiva social y cultural, como una actividad que permite preservar, poner en valor y difundir el patrimonio cultural local, generar los recursos necesarios para que dicho patrimonio pueda ser conservado, e impulsar nuevos emprendimientos o empleos con la finalidad de ofrecer oportunidades de trabajo y arraigo para las generaciones más jóvenes.

\section{Bibliografía}

Alburquerque, F.

2009. La crisis financiera y el desarrollo económico territorial, en Actas del V Congreso de la red DETE ALC, 6-7 de mayo 2009, Rafaela, Santa Fe, Argentina.

Alburquerque, $\mathrm{F}$.

2007. "Teoría y práctica del enfoque del desarrollo local", en Revista OIDLES (Observatorio Iberoamericano

del Desarrollo Local y la Economía Social), Vol 1, No 0. Disponible en http://www.eumed.net/rev/

oidles/00/Alburquerque.htm (fecha de consulta: enero 2015)

Antón Clavé, S. y F. González Reverté

2005. Planificación territorial del turismo. Editorial UOC, Universidad Oberta de Cataluña, Barcelona. Baeza, S.; Correa, D.

2011. "Impacto del Turismo Cultural en la Isla de Chiloé", en Revista Interamericana de Ambiente y

Turismo, Vol 7, $\mathrm{N}^{\circ}$ 1. Disponible en: http://riat.utalca.cl/index.php/test/article/viewFile/216/78 (fecha de consulta: octubre 2018). 
Barrera, E.

2009. "Las Rutas Alimentarias como instrumento para el desarrollo territorial: el caso de la Ruta de la Yerba Mate de Argentina”, en Revista Universidad de Sonora, № 26, julio - septiembre, México. Benedetto, A.

2007. "Valorización de la identidad territorial, políticas públicas y estrategias de desarrollo territorial en los países del MERCOSUR”, en Fonte, M. y C. Ranaboldo (Eds.) Territorios con identidad cultural. Perspectivas desde América Latina y la Unión Europea, Universidad Externado de Colombia, Bogotá.

Boschi, A.; García, M.

2011. "Nuevos Productos Turísticos: Ruta del Vino de la Patagonia en el Valle del Río Negro y Neuquén. Argentina", en Anuario de Estudios en Turismo - Investigación y Extensión, Año 11, Volumen VII, Facultad de Turismo, Universidad Nacional del Comahue, Neuquén, Argentina. Disponible en: http://170.210.83.98:8080/jspui/bitstream/123456789/203/1/Articulo5_Boschi_Garcia.pdf (fecha de consulta: octubre 2018).

Camou, C.

2010. "La dinámica del proceso de planificación y gestión del turismo en el espacio rural". Proyecto Nacional de Turismo Rural - Pronatur. Ministerio de Agricultura, Ganadería y Pesca de la Nación, Ministerio de Turismo de la Nación (MINTUR) - Instituto Nacional de Tecnología Agropecuaria (INTA). Disponible en http://www.pronatur.gov.ar/phocadownload/la\%20dinmica\%20del\%20proceso $\% 20$ de\%20planificacin\%20y\%20gestin\%20del\%20turismo\%20en\%20el\%20espacio\%20rural.pdf (fecha de consulta: noviembre 2013).

OIT-CIF - Organización Internacional del Trabajo - Centro Internacional de Formación

2004. Turismo y desarrollo local sostenible: elementos para un debate. Noticias Delnet, Revista electrónica del Programa Delnet de Desarrollo Local, $N^{\circ} 34$.

Domínguez de Nakayama, L.

1994. Relevamiento Turístico, Centro de Estudios Turísticos del Instituto Superior de Turismo "Sol”, Santa Fe.

EGES - Equipo de Gestión Económica y Social

2009. Provincia de Entre Ríos, Informe de situación. Disponible en http://www.eges.com.ar/archivos/ informes/1258722832_informe-entre-rios.pdf (fecha de consulta: noviembre 2013).

Ejarque, J.

2005. Destinos turísticos de éxito. Diseño, creación, gestión y marketing. Ed. Pirámide, Madrid.

Firpo, A.

1998. Los alemanes en la provincia de Entre Ríos, Consejo Federal de Inversiones, Paraná.

Flores, F. C.

2003. "Vivienda y pautas culturales. La organización de la vivienda y el espacio cotidiano en las colonias rusoalemanas de Argentina”, en Scripta Nova Revista Electrónica de Geografía y Ciencias Sociales, Vol. VII, Nro. 146(068), Universidad de Barcelona.

Fonte, M.

2009. "Hacia un sesgo rural en el desarrollo económico: la valorización de la riqueza cultural de América Latina", en Ranaboldo, C. y A. Schejtman (Eds.). El valor del patrimonio cultural. Territorios rurales, experiencias y proyecciones latinoamericanas, Instituto de Estudios Peruanos-IEP/Rimisp - Centro Latinoamericano para el Desarrollo Rural, Lima

Fuchs. G.

2009. Historia del ladrillo. Trabajo de investigación producido en el marco de una muestra de recuperación del patrimonio cultural denominado Wurzeln (Raíces), Aldea San Juan (inédito).

Fundación DEMUCA

2009. Guía práctica para el Agente de Desarrollo Local de Centroamérica y República Dominicana, Fundación DEMUCA y CEDeT, San José, Costa Rica.

GIZ - Programa de Cooperación Alemana

2016. Programa de Promoción del Desarrollo Económico Rural Sostenible. Disponible en: https://www. giz.de/en/downloads/giz2016-es-Fact_Sheet_PRODES.pdf ó https://www.giz.de/en/worldwide/35343. html (fecha de consulta: octubre 2018).

Hernández Asensio, R.

2009. "Posibilidades y límites de las estrategias de desarrollo local basadas en la identidad cultural en el valle del Colca (Arequipa, Perú)", en Ranaboldo, C. y Schejtman, A. (eds.), El valor del patrimonio cultural: territorios rurales, experiencias y proyecciones latinoamericanas, IEP-RIMISP; Territorios con Identidad Cultural, Serie Estudios de la Sociedad Rural, 35, Perú. 
ICOMOS - International Council on Monuments and Sites

1999. Carta Internacional sobre Turismo Cultural, $8^{\circ}$ Borrador, México.

Leader - Observatorio Europeo

1997. Evaluar el potencial turístico de un territorio, Guía metodológica, Cuadernos LEADER II, Comisión

Europea, Dirección General de Agricultura.

Leno Cerro, F.

1993. Técnicas de evaluación del potencial turístico. Secretaría General de Turismo, Dirección General de Política Turística, Madrid.

Madoery, O.

2008. Otro desarrollo. El cambio desde las ciudades y regiones. $1^{\circ}$ ed., UNSAM EDITA, Universidad

Nacional de San Martín, Buenos Aires.

MINTUR - PROFODE

2012. Ministerio de Turismo de la Nación, Argentina. Ficha de postulación e Instructivo. Programa de Fortalecimiento y Estímulo a Destinos Turísticos Emergentes (PROFODE), Dirección de Desarrollo de la Oferta, Subsecretaría de Desarrollo Turístico. Disponible en http://desarrolloturistico.gob.ar/ recursos/profode/PROFODE\%20Ficha\%20Convocatoria\%202013.pdf (fecha de consulta: noviembre 2012).

MINTUR

2011. Ministerio de Turismo de la Nación Argentina. Plan Federal de Turismo Sustentable. Actualización 2011. Turismo 2020. Disponible en http://siet.desarrolloturistico.gov.ar/recursos/documentos/SubDoc/ fd217bc5b686d951cdc21ec84792279335f7f055.pdf (fecha de consulta: noviembre 2012).

Navarro, M.

2002. "Patrimonio religioso en espacio rural: Las capillas del Bajo Valle del Río Chubut, Argentina", en Schluter, R. y J. Norrild (Coord.) Turismo y patrimonio en el siglo XXI, Centro de Investigaciones y Estudios Turísticos, Buenos Aires.

OIT-CIF

2015a. Organización Internacional del Trabajo-Centro Internacional de Formación. "Diagnóstico y planificación estratégica, ejes centrales de una política local de turismo sostenible", en Curso de Turismo Sostenible y Desarrollo Local, Unidad Didáctica 5, Programa Delnet de Apoyo al Desarrollo Local, Centro Internacional de Formación, Turín.

OIT-CIF

2015 . "Gestión del desarrollo local basado en el turismo", en Curso de Turismo Sostenible y Desarrollo Local, Unidad Didáctica 4, Programa Delnet de Apoyo al Desarrollo Local, Centro Internacional de Formación, Turín.

OMT - Organización Mundial del Turismo

1999. Guía para Administraciones Locales: Desarrollo turístico sostenible, Madrid, España.

OMT - Organización Mundial del Turismo

2013. Estudio sobre el turismo y el patrimonio cultural inmaterial. Resumen de los resultados. Disponible en: http://cf.cdn.unwto.org/sites/all/files/docpdf/summarytourismandichstudy120512esprint.pdf (fecha de consulta: junio 2018).

OMT - Organización Mundial del Turismo

2018. Tourism for Development - Volume II: Success Stories, UNWTO, Madrid. Disponible en: https:// doi.org/10.18111/9789284419746 (fecha de consulta: junio 2018).

OMT - Organización Mundial del Turismo

2018. Tourism and Culture Synergies, UNWTO, Madrid. Disponible en: https://doi.org/10.18111/9789284418978 (fecha de consulta: junio 2018).

OMT - OEA

2018 Organización Mundial del Turismo - Organización de los Estados Americanos. Tourism and the Sustainable Development Goals - Good Practices in the Americas, UNWTO, Madrid. Disponible en: https://doi.org/10.18111/9789284419685 (fecha de consulta: junio 2018).

OMT-PNUD

2017. Organización Mundial del Turismo -Programa de Naciones Unidas para el Desarrollo. Tourism and the Sustainable Development Goals - Journey to 2030. Disponible en: https://www.e-unwto.org/ doi/pdf/10.18111/9789284419401 (fecha de consulta: junio 2018). 
ONU - Organización de Naciones Unidas

2012. Documento Final de la Conferencia sobre el Desarrollo Sostenible Río + 20, Río de Janeiro, Brasil. http://www.un.org/es/comun/docs/?symbol=A/CONF.216/L.1 (fecha de consulta: noviembre 2013).

Owen, O.; Hughes, J.

2009. "Atractivos histórico-culturales producto de la colonización galesa", en Revista Párrafos Geográficos, Instituto de Investigaciones Geográficas de la Patagonia (IGEOPAT), Universidad Nacional de la Patagonia San Juan Bosco, Comodoro Rivadavia.

Rodil, D.; Alemany, C.

2010. "La ruta del vino. Un caso de autonomización de los actores locales", en Primer Encuentro Nacional de Economía Agraria y Extensión Rural, AADER-AAEA y XV Jornadas Nacionales de Extensión Rural, VII del MERCOSUR, Potrero de los Funes, San Luis, Argentina. Disponible en: https://inta.gob.ar/ sites/default/files/script-tmp-sistematizacion_ruta_del_vino.pdf (fecha de consulta: octubre 2018).

Scalise, J.

2012. Herramientas, técnicas y conceptos claves para el desarrollo del turismo rural, $1^{\circ}$ edición, Ed. PROSAP, Buenos Aires. Disponible en: http://www.ucar.gob.ar/images/publicaciones/Herramientas\%20 t\%C3\%A9cnicas\%20y\%20conceptos\%20claves\%20para\%20el\%20desarrollo\%20del\%20turismo\%20 rural.pdf (fecha de consulta: octubre 2018).

Secretaría de Turismo de Entre Ríos

2011. Plan Estratégico de Desarrollo Turístico Sustentable de la Micro Región El Paraná y sus Aldeas. PDETS 2011-2020. Programa de Fortalecimiento Institucional Productivo y de Gestión Fiscal Provincial - PROFIP.

Toselli, C. y F. Godoy

2011. Circuitos de Turismo Cultural. Inventario preliminar del patrimonio tangible en aldeas rurales de alemanes del Volga, Pcia. de Entre Ríos, Argentina, Revista Estudios del IMAE Nro. 15, Instituto de Medio Ambiente y Ecología, Vicerrectorado de Investigación y Desarrollo, Universidad del Salvador, Buenos Aires.

Toselli, C.; ten Hoeve, A.; de Mahieu, G.

2015. "Propuesta de circuito turístico-cultural en el Corredor del río Uruguay, Entre Ríos, Argentina. Relato de una experiencia", en PASOS, Revista de Turismo y Patrimonio Cultural, Vol. 13, Nro. 5, Universidad de La Laguna, Instituto Universitario de Ciencias Políticas y Sociales, Tenerife, España. Disponible en: http://www.pasosonline.org/articulos/840-propuesta-de-circuito-turistico-cultural-en-el-corredor-del-rio-uruguay-entre-rios-argentina-relato-de-una-experiencia (fecha de consulta: enero 2017)

UNESCO - Organización de las Naciones Unidas para la Educación, la Ciencia y la Cultura

2015. Turismo cultural. Hacia un turismo reflexivo y atento a la cultura del otro. Disponible en: http:// portal.unesco.org/culture/es/ev.php-URL_ID=36700\&URL_DO=DO_TOPIC\&URL_SECTION=201. html (fecha de consulta: enero 2015)

UNESCO - Organización de las Naciones Unidas para la Educación, la Ciencia y la Cultura

2007. Estrategia a Plazo Medio para 2008-2013, París.

UNESCO - Organización de las Naciones Unidas para la Educación, la Ciencia y la Cultura

2003. Convención para la salvaguardia del patrimonio cultural inmaterial, París, 17 de octubre 2003. Disponible en http://unesdoc.unesco.org/images/0013/001325/132540s.pdf_(fecha de consulta: mayo 2015).

UNESCO - Organización de las Naciones Unidas para la Educación, la Ciencia y la Cultura

1972. Convención sobre la Protección del Patrimonio Mundial Cultural y Natural, París, 16 de noviembre de 1972. Disponible en http://portal.unesco.org/es/ev.php-URL_ID=13055\&URL_DO=DO_TOPIC\&URL_ SECTION=201.html (fecha de consulta: mayo 2018).

Valls, J.

1996. Las claves del mercado turístico. Cómo competir en el nuevo entorno, Ed. Deusto, Bilbao.

Varisco, C.; Castellucci, D.I.; González, M. G.; Muñoz, M. J.; Campoliete, L.; Padilla, N.; Benseny, G.

2014. El relevamiento turístico: de CICATUR a la planificación participativa. VI Congreso Latinoamericano de Investigación Turística, Neuquén. Disponible en Portal de Promoción y Difusión Pública del Conocimiento Académico y Científico, Facultad de Ciencias Económicas y Sociales, Universidad Nacional de Mar del Plata, http://nulan.mdp.edu.ar/2052/1/varisco.etal.2014.pdf (fecha de consulta: febrero 2015) 
Vázquez Barquero, A.

2009. "Desarrollo Local, una estrategia para tiempos de crisis", en Universitas Forum: International Journal on Human Development and International Cooperation, Vol. 1, No. 2. Disponible en http:// hdrnet.org/444/1/barquero_UF2.pdf (fecha de consulta: marzo 2013).

Vázquez Barquero, A.

1998. Desarrollo económico local y descentralización: Aproximación a un marco conceptual, Proyecto CEPAL/GTZ Desarrollo económico local y descentralización, Santiago de Chile.

Vereda, M., Salemme, M.; Daverio, M.E. y S. Alazard

2002. "Recursos culturales y paisajes naturales. Una aproximación turística para la revalorización del patrimonio", en Schlüter. R. y J. Norrild (Coord.) Turismo y Patrimonio en el Siglo XXI, Centro de Investigaciones y Estudios Turísticos (CIET), Buenos Aires.

Wallingre, $\mathrm{N}$.

2014. "Instrumentos para el diagnóstico integral de la oferta en destinos turísticos", en Wallingre, N. y A. Villar (Comp.). Gestión de municipios turísticos. Instrumentos básicos de acción, Universidad Nacional de Quilmes, Bernal.

Wallingre, $\mathrm{N}$.

2017. "Enfoques del desarrollo y el turismo en América Latina”, en Divulgatio, Vol. 1 Núm. 3, Bernal, Universidad Nacional de Quilmes. Disponible en: http://revistadivulgatio.web.unq.edu.ar/?entradas-ejemplares=enfoques-del-desarrollo-y-el-turismo-en-america-latina (fecha de consulta: mayo 2018).

\section{Notas}

1 Artículo adaptado en base a la Tesis de Maestría en Desarrollo Local de la Universidad Nacional de San Martín (Argentina) y la Universidad Autónoma de Madrid (España) titulada: "Turismo, patrimonio cultural-rural y desarrollo local. Evaluación del potencial turístico de las aldeas alemanas del Volga, micro región Pueblos del Sur entrerriano (Provincia de Entre Ríos, Argentina)". Tesista: Claudia Toselli; Directora de tesis: Genoveva de Mahieu. El proyecto de tesis fue seleccionado en el marco del Programa PROFITE del Ministerio de Educación de la Nación, Argentina (2013-2015).

2 Según el Diccionario de la Real Academia Española (http://lema.rae.es/drae/?val=aldea) se entiende por "aldea" al pueblo de corto vecindario y, por lo común, sin jurisdicción propia. Se lo define también como "pueblo pequeño donde la población tiene una fuerte relación con el campo" (Ministerio de Educación, Ciencia y Tecnología de la Nación, 2005).

3 El desarrollo local o endógeno consiste básicamente en los recursos tangibles que dispone un territorio, pero también en los recursos intangibles, como son las capacidades que poseen las personas e instituciones que lo integran, relacionadas con la búsqueda de consensos, la creatividad, la innovación, la fuerza emprendedora, la comunicación, la asociación, la articulación, y las formas de organización, decisión y control que los actores ejercen sobre el propio territorio para mejorar su calidad de vida. En síntesis, plantea que el desarrollo local es un proceso controlado por los actores locales, donde es particularmente importante la capacidad de gestionar los propios recursos, sabiendo aprovechar estratégicamente los recursos externos, donde resultan fundamentales las capacidades locales, y donde además predomina la mirada "abajo-arriba", es decir tomar el control desde las bases, asumiendo los actores locales el protagonismo de su propio proceso de desarrollo (Madoery, 2008).

4 Según el ICOMOS (1999) el patrimonio cultural "es amplio e incluye sus entornos tanto naturales como culturales. Abarca los paisajes, los sitios históricos, los emplazamientos y entornos construidos, así como la biodiversidad, los grupos de objetos diversos, las tradiciones pasadas y presentes, y los conocimientos y experiencias vitales".

5 Fuchs, C. Responsable del Area Cultura, Turismo y Deporte, Municipalidad de Aldea San Antonio, comunicación personal.

6 Datos correspondientes al año 2015.

7 Gualeguaychú es una ciudad donde el sector turístico constituye la base su economía, conjuntamente con la actividad agropecuaria e industrial, fundamentalmente en los rubros de productos alimenticios. Esta localidad, doblemente ribereña ya que por ella pasan el río Gualeguaychú y el río Uruguay, se enmarca en un agradable paisaje litoral, con numerosos espacios verdes dentro del espacio urbano. Asimismo, es destino turístico posicionado a nivel nacional, por su atractivo basado en las playas y las fiestas de carnaval que se realizan durante los meses de enero y febrero.

8 La localidad de Urdinarrain cuenta con 8.986 habitantes. Tiene la particularidad de haber transformado la estación de ferrocarril en el Complejo "La Estación"- construcción típica de la arquitectura inglesa de fines del siglo XIX y recuperada como patrimonio por el municipio en 1998. Allí se encuentra el Museo Histórico Regional donde se exhiben objetos y escenas de la vida del pueblo, además de muestras de arte y artesanías locales tradicionales y urbanas.

9 La micro región "Pueblos del Sur Entrerriano" - conformada entre los años 2000 y 2015 (con sus altos y bajos según los cambios políticos municipales) - recorría de manera circular unos $130 \mathrm{~km}$ aproximadamente, incluyendo las siguientes localidades y pueblos rurales: Gualeguaychú, Pueblo Belgrano, Larroque, Irazusta, Parera, Urdinarrain, Escriña, Gilbert y las Aldeas San Antonio, San Juan y Santa Celia. Todos estos sitios tienen en común la puesta en valor de las tradiciones rurales y las costumbres de los inmigrantes europeos que se radicaron en esas tierras a fines del siglo XIX. La conformación de estas micro regiones fue impulsada por el gobierno provincial durante esos años, con el fin de asociar unidades territoriales vecinas para integrar el esfuerzo de varias jurisdicciones municipales, y así consolidar las relaciones sociales entre los actores intervinientes, fortalecer la identidad local, posibilitar la integración a la oferta turística provincial, generar una mayor diversidad de atractivos, reducir los costos, equilibrar las temporadas, aumentar los índices de permanencia y promover un mayor movimiento económico. 
10 La descripción de cada uno de estos platos se puede observar a continuación:

- Prode: comida que consiste en carne de cerdo ó pollo con batatas cocidas en horno de barro.

- Krau piroc: masa de harina y levadura que se rellena con carne picada, repollo y cebolla rehogada. Luego se cocinan al horno en diversas formas, pero generalmente es cuadrada.

- Dinne Kuchen: masa de harina, levadura, azúcar quemada y caramelo.

- Kreppel: masa que consiste en leche cortada, harina, huevo y crema. Con esa mezcla se elabora una trenza y se fríe. Luego se espolvorea con azúcar impalpable.

11 Quast: bebida autóctona de los alemanes del Volga elaborada con cebada cervecera, harina de maíz, levadura casera, afrechillo de trigo y azúcar.

12 En algún momento también tuvo lugar una pequeña sala de exposición en el edificio municipal, denominado Museo "Andenken" (recuerdos), con objetos y elementos vinculados a la historia de los primeros pobladores. Luego esta sala tuvo que ser utilizada para otras actividades y los objetos se conservan guardados, siendo exhibidos solo durante la Fiesta del Inmigrante Alemán. 